\title{
IMPROVEMENT OF MICROMERITIC, COMPRESSIBILITY AND SOLUBILITY CHARACTERISTICS OF LINEZOLID BY CRYSTALLO-CO-AGGLOMERATION TECHNIQUE
}

\author{
ATUL M. KADAM*, SHITALKUMAR S. PATIL \\ Department of Pharmaceutics, Ashokrao Mane College of Pharmacy, Peth-Vadgaon, Shivaji University, Kolhapur, Maharashtra, India \\ Email: atulpharma@gmail.com
}

Received: 04 Apr 2017, Revised and Accepted: 14 Jun 2017

\begin{abstract}
Objective: The purpose of current study was to improve physicochemical properties such as micrometric, compressibility and solubility of linezolid (LNZ) by preparing crystallo-co-agglomerates (CCA) in the presence of polymer for the enhancement of overall physicochemical performance.

Methods: The process of agglomeration involves the use of dichloromethane (DCM) as a good solvent and chloroform as bridging liquid were used to prepare agglomerates. Agglomerates were characterised in the solid state using several techniques such as Scanning electronic microscopy(SEM), Fourier transformation infrared spectroscopy (FTIR), X-ray powder diffraction analysis (XRPD) The agglomerates obtained were evaluated for
\end{abstract} micrometric, mechanical, deformation, compressibility and drug release properties.

Results: It was found that micrometric properties and dissolution characteristics of agglomerates were significantly improved than that of pure linezolid. Solubility was found to be increased than pure linezolid. The solubility of crystallo co-agglomerates was found an increase in 5 fold 3 fold and 3.7 fold for PVPK30 (0.5\%), PVPK30 $(0.25 \%)$ and PVPK30 (0.75\%) respectively. The angle of repose for all batches was found between $22{ }^{\circ}$ to $30^{\circ}$ Carrs index was between $12.27 \pm 0.6$ to $18.73 \pm 0.4$ and Hausners ratio Near to 1 , indicated good flow ability of agglomerates. The time required for drug release over a period of $60 \mathrm{~min}$, is as LA1>LA2>LA3. LA3 shows fast drug release than LA1 and LA2, due to solubilization of drug due to more concentration of PVPK30 and less concentration of talc.

Conclusion: Based on the above results, it was revealed that CCA of linezolid prepared with DCM and HPMC (Hydroxypropyl methyl cellulose)/PEG (Polyethylene glycol)/PVP (Polyvinylpyrrolidone) K30 exhibited improved micrometric properties, compressibility and in addition to improving solubility and dissolution rate.

Keywords: Crystallo-co-agglomeration, Good solvent, Micrometrics, Linezolid, Direct compression

(C) 2017 The Authors. Published by Innovare Academic Sciences Pvt Ltd. This is an open access article under the CC BY license (http://creativecommons.org/licenses/by/4.0/) DOI: http://dx.doi.org/10.22159/ijap.2017v9i4.18915

\section{INTRODUCTION}

The focus of today's pharmaceutical industry is to better drug delivery concepts but also makes the simple standard formulations as economical as possible to produce. One of the most economical solutions is to find directly compressible formulations and this is especially at interest for large volume products. There is an interest in examining the potential of direct compression tabletting in recent years over traditional granulation process. Such manufacturing of the tablets involves simple mixing and compression of powders which gives benefits like time and cost saving [1]. Thus direct tabletting technique has been widely used successfully for various drugs. However, compressing a drug directly requires good micromeritic properties, such as flowability, good reproducible compression behaviour as it affects in vitro and in vivo performance of pharmaceuticals $[2,3]$, But it strongly depends upon the quality of the crystals used. To impart these properties the drugs are subjected to particle design techniques, spherical crystallization is one of the techniques of particle design $[4,5]$. By this technique manufacturing process highly improved also a high degree of particle functionality is achieved [6].

In the pharmaceutical field, Kawashima et al. have given an impulse to the research of the spherical crystallization process. "Spherical crystallization" was defined by Kawashima as "an agglomeration technique that transforms crystals directly into a compacted spherical form during the crystallization process." Spherical crystallization is a particle design technique which is restricted to only water insoluble single large dose drugs only because several excipients are hydrophilic in nature hence the addition of these excipients in the agglomerates with the help of organic bridging liquid is difficult [7]. Kadam et al. developed the CCA technique, which is a modification of spherical crystallization. CCA has been designed to overcome the limitations of spherical crystallization to obtain directly compressible agglomerates [8, 9]. Basically, it's single step process used for size enlargement of single, two or more, small dose or large dose drugs, in combination with or without diluents. The process of CCA involves simultaneous crystallization and agglomeration of drug/s with/without excipients from the good solvent and/or bridging liquid by addition of a non-solvent [10,11]. The tablet dosage form prepared from agglomerated crystals showed improvements in tensile strength, hardness, friability, disintegration time and dissolution rate as compared to tablets prepared from granules. Thus this technique of particle design of drugs has emerged as one of the areas of active research in pharmaceutical manufacturing which is simple, less expensive and advantages for developing it on a commercial scale for manufacturing of tablets gained great attention and importance due to the fact that crystal habit (form, surface, and size and particle size distribution) can be modified during the crystallization process $[12,13]$.

LNZ is poorly water soluble belong to Biopharmaceutical Classification System (BCS) Class IV drug. Generally inadequate solubility and dissolution rate are the problems associated with a stable crystalline form that results in poor oral absorption and less bioavailability. Nowadays crystallo-co-agglomeration technique has been attracting the attention of researchers for increasing the solubility, dissolution and micrometric properties of the drug [14, 15]. The present study is an attempt to improve physicochemical properties such as micrometric properties, compressibility, solubility and or dissolution of LNZ using CCA technique. The choice of drug was made on the basis of significant compressibility and solubility problems associated with the drugs. CCA of LNZ prepared in the presence of polymer (hydrophilic carrier) for the enhancement of overall physicochemical performance. In this process, LNZ was crystallized from DCM as a good solvent and agglomerated with excipients in the presence of chloroform as bridging liquid. Physicochemical properties of raw LNZ and its agglomerates were characterized in the solid state using techniques such as SEM, FTIR, DSC, XRPD, solubility studies and dissolution test. The improvement in micromeritic properties was determined by 
calculating the angle of repose, Hausner ratio, Carr's index of LNZ and its agglomerates respectively.

\section{MATERIALS AND METHODS}

\section{Material}

LNZ was obtained as a gift sample from Bharat Pharmaceuticals Thane, India. PEG 6000, PVP K30, Dichloromethane and Chloroform were procured from SD fine chemicals, Mumbai, India. All other chemicals and reagents used were of analytical grade

\section{Method}

LNZ and HPMC were dissolved in $25 \mathrm{ml}$ DCM (good solvent) and 4 $\mathrm{ml}$ chloroform (bridging liquid) and talc were uniformly dispersed in it. The resultant solution was poured into $50 \mathrm{ml}$ of water containing PEG6000 and PVPK30 with stirring at 800 revolutions per min (rpm). The stirring was continued to obtain agglomerates, which were then filtered and dried overnight at room temperature. Above process was repeated more than 3 times to obtain adequate materials for characterization and to observe repeatability. Formulation codes with the proportion of excipients used for CCA of LNZ are as given in table 1.

\section{Saturation solubility studies}

Solubility studies were carried out in distilled water according to the method reported by Higuchi and Connors [16]. Excess quantity of LNZ and its prepared CCA were introduced in $20 \mathrm{ml}$ of distilled water and shaken for $24 \mathrm{~h}$ at room temperature. The content of each flask was then filtered through a Whatmann filter paper. The filtrate was then diluted and assayed spectrophotometrically at $251 \mathrm{~nm}$. Each solubility was determined in triplicate $(n=3)$. The results obtained from saturation solubility studies were statistically analyzed.

Where, L: linezolid, LA1: linezolid+talc (1:1), LA2 (linezolid+talc (1:0.75), LA3: linezolid+talc (1:0.5)

Table 1: Formulation of linezolid CCA

\begin{tabular}{|c|c|c|c|}
\hline Ingredients & LA1 & LA2 & LA3 \\
\hline Linezolid & $100 \mathrm{mg}$ & $100 \mathrm{mg}$ & $100 \mathrm{mg}$ \\
\hline Talc & $100 \mathrm{mg}$ & $75 \mathrm{mg}$ & $50 \mathrm{mg}$ \\
\hline HPMC E50LV (\%wt/wt of solids) & $5.0 \%$ & $5.0 \%$ & $5.0 \%$ \\
\hline PEG $6000(\% \mathrm{w} / \mathrm{w}$ of solid $)$ & $6.0 \%$ & $6.0 \%$ & $6.0 \%$ \\
\hline PVP K30 (\% w/w of drug) & $0.25 \%$ & $0.5 \%$ & $0.75 \%$ \\
\hline
\end{tabular}

\section{Process yield and drug content}

The percent yield of the agglomerate was determined by applying the mass balance equation to the process. The drug content was determined for each batch separately in triplicate. For determination of drug content in agglomerates were powdered and from which powder equivalent to $10 \mathrm{mg}$ of linezolid was weighed from each batch and added to a solvent system containing DCM $10 \mathrm{ml}$ and sonicated for $15 \mathrm{~min}$. Appropriately diluted samples were filtered through whatman filter paper (pore size $0.45 \mu \mathrm{m})$ and drug content was determined spectrophotometrically at $251 \mathrm{~nm}$ for LNZ using UV-Visible spectrophotometer. The percentage drug content was calculated using following formula given below. All analyses were carried out in triplicate [17].

$$
\text { Percentage yield }=\frac{\text { Total weight of agglomerate }}{\text { Total weight of drug and polymer }} \times 100 \text {---------(1) }
$$$$
\text { Percentage Drug content }=\frac{\text { Practical Drug concentration }}{\text { Theortical Drug concentration }} \times 100 \text {----------(2) }
$$

\section{Scanning electron microscopy (SEM)}

The surface morphological properties of pure drug and CCA were investigated by scanning electron microscopy (SEM-Jeol Instruments, JSM-6360, Japan). Samples were mounted on a double-faced adhesive tape, sputtered with gold. Scanning electron photographs were taken at an accelerating voltage of $15 \mathrm{kV}$ and obtained micrographs were examined at X2000, X5000, X10000 and X15000 magnifications.

\section{X-Ray powder diffractometry (XRPD)}

The XRPD data of pure drug and CCA were recorded on a Philips Analytical X-ray-PW 3710 (Phillips, Almedo, The Netherlands) diffractometer with tube anode $\mathrm{Cr}$ over the interval $10-70 \% / 2 \theta$ under following a set of conditions: The generator tension (voltage): $40 \mathrm{kV}$ and generator current: $25 \mathrm{~mA}$.

\section{Differential scanning calorimetry (DSC)}

DSC studies were carried out using Mettle-Toledo DSC 821 instrument. Indium and zinc standards were used to calibrate the DSC temperature and enthalpy scale. A powdered sample was hermetically sealed in aluminium crucibles and heated at a constant rate of $10{ }^{\circ} \mathrm{C} / \mathrm{min}$ over a temperature range of $25-250$ ${ }^{\circ} \mathrm{C}$. Inert atmosphere was maintained by purging nitrogen gas at a flow rate of $50 \mathrm{ml} / \mathrm{min}$. results were obtained in triplicates for each sample [18].

\section{Fourier transformation infrared spectroscopy (FTIR)}

FTIR spectra of Pure drug obtained using a Shimadzu FTIR spectrometer (Agilent Technologies, carry 630 FTIR) spectrometer. The scanning range was kept from 4000 to $400 \mathrm{~cm}-1$. Similarly, the spectra of polymers and physical mixtures were taken.

\section{Measurement of flowability}

Flowability of pure linezolid and their prepared agglomerates were determined in terms of angle of repose, Carr's compressibility index and Hausner ratio. The angle of repose of drug powder and the agglomerates were assessed by fixed funnel method. The Carr's index reflects the compressibility of the agglomerates and there is a correlation between the compressibility index and the flowability of the CCA. The results presented are mean $\pm \operatorname{SD}(n=3)$.

\section{Pressure-tensile strength $(\sigma t)$ relationship}

Same data were used as to Pressure-relative density relationship study and force (F) measured required for fracturing the compacts determined by a Monsanto-type hardness tester. The data were subjected to tensile $(\sigma t)$ determination using following equation [19-21].

$$
\sigma \mathrm{t}=2 \mathrm{~F} / \pi \mathrm{Dt}--------(3)
$$

Where, $\mathrm{D}$ and $\mathrm{t}$ are diameter and thickness respectively, of the compacts, used.

\section{Pressure-relative density relationship}

The compressibility behaviors of the agglomerates were studied using Heckel equation. Intact agglomerates $(225 \pm 5 \mathrm{mg})$ of LA1, LA2, LA3 were compressed separately by using a hydraulic press (Spectra Lab, Mumbai, Maharashtra, India) having a $8 \mathrm{~mm}$ flat-faced punch and die set at pressures of $0.5,0.7,1.0,1.2,1.5$ and 3.0 tons for $1 \mathrm{~min}$ of dwell time. Lubrication of the die and punches was performed by a $1 \% \mathrm{wt} / \mathrm{vol}$ dispersion of magnesium stearate in acetone. Compacts were allowed to relax for $24 \mathrm{~h}$ at ambient conditions. The weight, diameter and thickness of the compacts were determined. The data were processed using following equation.

$$
\ln \ln (1 / 1-D)=K P+A----(4)
$$

Where $\mathrm{D}$ and $\mathrm{P}$ are the packing fraction and applied pressure respectively. $K$ is Heckel constant equal to $1 / 3 \sigma 0$, $\sigma 0$ is yield strength and $3 \sigma 0$ is mean yield strength (MyP). A is constant. 


\section{Dissolution studies}

The dissolution rate studies of LNZ alone and prepared agglomerates were performed in triplicate using a USP Type II dissolution apparatus paddle method (Lab India, Model Disso 2000 Tablet dissolution test apparatus, Mumbai, India). Dissolution studies were carried out using $900 \mathrm{ml}$ of phosphate buffer (pH 6.8) at $37 \pm 0.5{ }^{\circ} \mathrm{C}$ at $50 \mathrm{rpm}$. The volume of dissolution medium was adjusted to $900 \mathrm{ml}$ by replacing each $5 \mathrm{ml}$ aliquot withdrawn with 5 $\mathrm{ml}$ of fresh phosphate buffer (pH6.8). The solutions were immediately filtered through a $0.45 \mu \mathrm{m}$ membrane filter, suitably diluted and the concentrations of linezolid in samples were determined spectrophotometrically at $251 \mathrm{~nm}$. The results of dissolution studies were statistically analyzed.

Release kinetics of LNZ from the compact. Intact agglomerates $(225 \pm 5 \mathrm{mg}$ ) of LA1, LA2 and LA3 were weighed and compressed by a hydraulic press having a $8 \mathrm{~mm}$ flat-faced punch and die set at 4 tons of pressure for $1 \mathrm{~min}$ of dwell time. The compacts obtained were subjected to dissolution in triplicate, similar to that of agglomerates. Each time, $5 \mathrm{ml}$ of sample was withdrawn and analyzed spectrophotometrically at $251 \mathrm{~nm}$. The same amount of fresh phosphate buffer (pH6.8) was used to replace the amount withdrawn.

\section{RESULTS AND DISCUSSION}

The performance of the CCA process was evaluated on the basis of ease of processing, agglomeration yield, and agglomerate handling qualities. All these process performance characteristics were observed in LA1, LA2 and LA3 batches.

\section{Saturation solubility studies}

Table 2 shows results of saturation solubility studies. The solubility of CCA was found to be increased than pure LNZ. There was 5 fold increase in case of PVPK30 (0.5\%), there was 3 fold while in PVPK30 $(0.25 \%)$ and in PVPK30 $(0.75 \%)$ ratio it was found to be 3.7 fold. The increment in solubility by crystallo-co-agglomeration was found to be a significant one. This might be due to changes in crystal habit, structure and surface morphology [21]. In addition to that, the solvent included in crystal form solvates that might have changed the reactivity of drug particles, surface morphology and internal energy of the molecules which would be responsible for increasing solubility of agglomerates [22].

Table 2: Saturation solubility of pure Linezolid and crystallo-co-agglomerates

\begin{tabular}{ll}
\hline Formulation & Saturation Solubility $\mathbf{( m g / m l )}$ \\
\hline L & $3.00 \pm 0.01$ \\
LA1 & $9.24 \pm 1.3$ \\
LA2 & 14.812 .1 \\
LA3 & $11.09 \pm 1.8$ \\
\hline
\end{tabular}

Results are mean of three determination $\pm \mathrm{SD}$

\section{Process yield}

For LA1, LA2 and LA3, the yield of agglomeration was76.85 $\pm 1.80 \%$ $\mathrm{w} / \mathrm{w}, 69.83 \pm 0.92 \% \mathrm{w} / \mathrm{w}$ and $69.23 \pm 0.98 \% \mathrm{w} / \mathrm{w}$ respectively. The drug content of agglomerates was $89.90 \pm 0.60 \% \mathrm{w} / \mathrm{w}, 94.30 \pm 1.25 \%$ $\mathrm{w} / \mathrm{w}, 96.20 \pm 0.99 \% \mathrm{w} / \mathrm{w}$ for LA1, LA2 and LA3, respectively. It was greater in the initial stages but later got reduced because of entrapment of HPMC during the progress of agglomeration.

Table 3: Actual yield, drug content and entrapment efficiency of crystallo-co-agglomerates of linezolid

\begin{tabular}{llll}
\hline S. No. & Batch code & Yield (\%) & Drug content (\%) \\
\hline 1 & LA1 & $76.85 \pm 1.80$ & $89.90 \pm 0.60$ \\
2 & LA2 & $69.83 \pm 0.92$ & $94.30 \pm 1.25$ \\
3 & LA3 & $69.23 \pm 0.98$ & $96.20 \pm 0.99$ \\
\hline
\end{tabular}

Results are mean of three determination \pm SD

Measurement of particle size distributions is routinely carried out across a wide range of industries and is often a critical parameter in the manufacture of many products. Mean particle size of linezolid was determined by randomly counting average diameter of 100 particles with an optical microscope (microscopy method). It was found that particle size of plane crystals and crystals with additives was increased than original crystals may be due to particle crystallisation is shown in table 4 [23]. The presence of DCM at the surface of the growing agglomerate, the agitation force, winter particulate attraction, and polymers (Talc, PEG and HPMC) influenced the size of agglomerates, as reported in earlier studies [16].
More linezolid loading in LA3 decreased the cohesive attraction, reducing the size of agglomerates, and the presence of HPMC increased the size of agglomerates because of increased viscosity of DCM. Here, increased viscosity reduced the destructive forces acting on the agglomerates. PEG, because of its tendency to reduce interfacial tension, is reported to generate smaller agglomerates [24, 25].

Lalla and Bhat have reported an angle of repose of $22^{\circ}$ to 30 for a spheronized product [26]. Hence, the observed angle of repose for all batches in the range of $22^{\circ}$ to $30^{\circ}$ indicated good flowability of agglomerates.

Table 4: Micromeritic properties of linezolid agglomerates

\begin{tabular}{|c|c|c|c|c|c|c|c|}
\hline S. No. & $\mathbf{F C}^{*}$ & $\begin{array}{l}\text { Diameter } \\
(\mu \mathrm{m}) \mathrm{n}=100\end{array}$ & $\begin{array}{l}\text { Angle of } \\
\text { repose }\left({ }^{\circ}\right)\end{array}$ & $\begin{array}{l}\text { Bulk } \\
\text { density (g/cc) }\end{array}$ & $\begin{array}{l}\text { Tap } \\
\text { density }(g / c c)\end{array}$ & $\begin{array}{l}\text { Carr's } \\
\text { Index (\%) }\end{array}$ & $\begin{array}{l}\text { Hausners } \\
\text { ratio } \\
\end{array}$ \\
\hline \multirow[t]{2}{*}{1} & LA1 & 637.8 & 25.33 & 0.255 & 0.315 & 12.27 & 1.17 \\
\hline & & \pm 0.94 & \pm 0.56 & \pm 0.007 & \pm 0.007 & \pm 0.6 & \pm 0.04 \\
\hline \multirow[t]{2}{*}{2} & LA2 & 592.3 & 22.13 & 0.263 & 0.329 & 13.98 & 1.16 \\
\hline & & \pm 1.13 & \pm 1.06 & \pm 0.005 & \pm 0.003 & \pm 0.3 & \pm 0.04 \\
\hline \multirow[t]{2}{*}{3} & LA3 & 560.2 & 30.16 & 0.269 & 0.331 & 18.73 & 1.23 \\
\hline & & \pm 1.05 & \pm 0.96 & \pm 0.008 & \pm 0.009 & \pm 0.4 & \pm 0.03 \\
\hline
\end{tabular}

*FC: Formulation Code, Results are mean of three determination \pm SD,

i.e. FTIR study of the drug and agglomerates showed all the peaks of the drug as shown in fig. 1,2. 


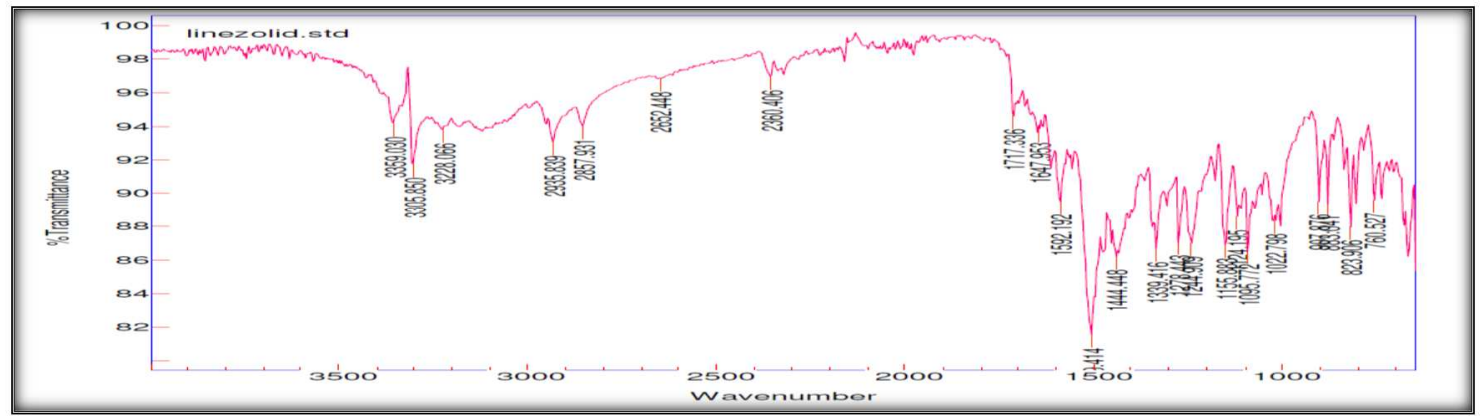

Fig. 1: FTIR spectra of standard linezolid

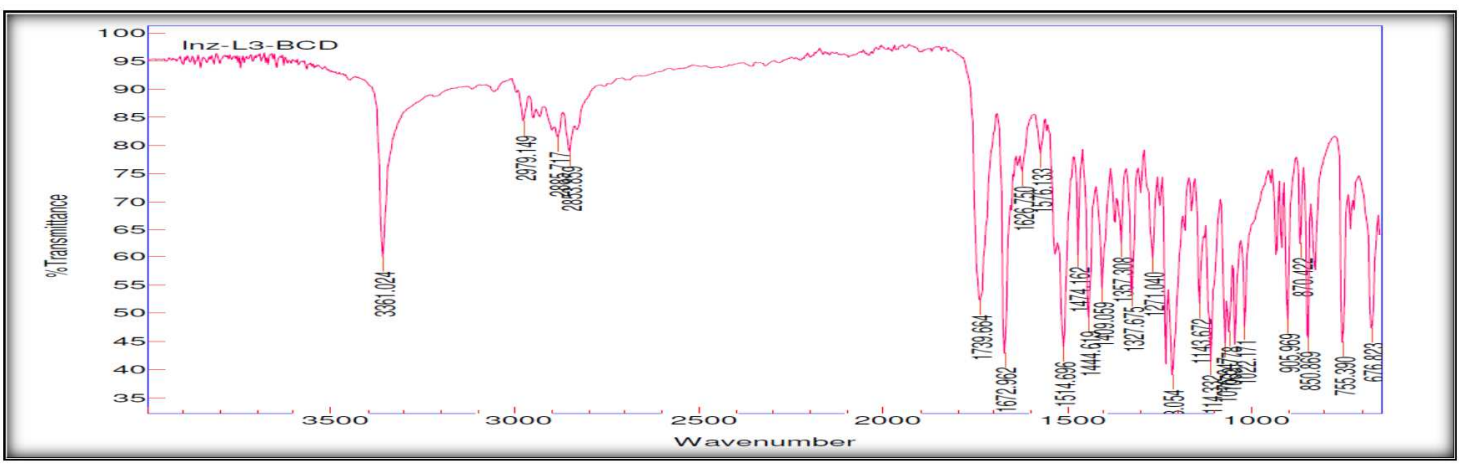

Fig. 2: Drug and excipients compatibility study

SEM gives information about the surface morphology of untreated pure drug and agglomerates. The pure drug in crystal needlelike while agglomerates show spherical structure as shown in fig. 3 , fig. 4 .

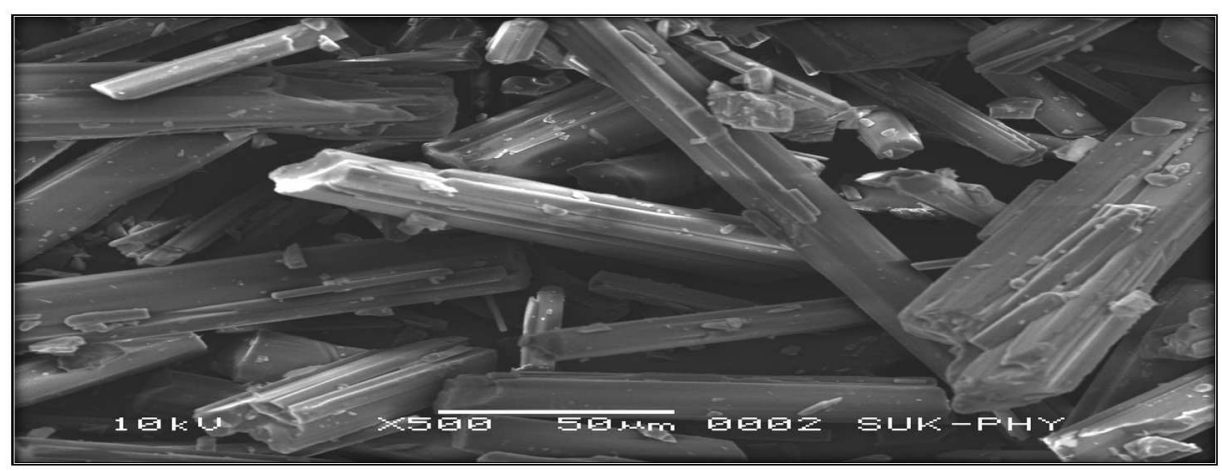

Fig. 3: Scanning electron microscopy of linezolid pure drug.

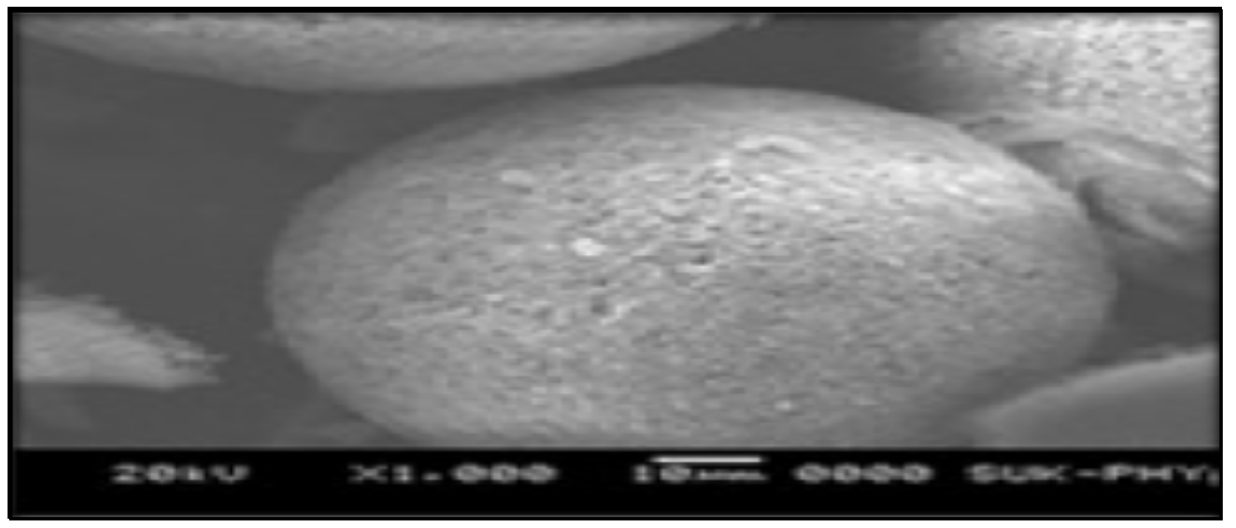

Fig. 4: Scanning electron microscopy of optimised batch of crystall-Co-agglomerates 
XRPD study is required for determination of crystal lattice and amorphous nature of drug or excipients. By using XRPD we can measure the average spacing between layers or rows of atoms, determine the orientation of a single crystal or grain. The XRPD study of pure linezolid shown in fig. 5. It reveals that the intensity of the peaks for the pure drug was showed sharp distinct peaks notably at $2^{\circ} \theta$ diffraction angles of $8.14^{\circ}, 12.15^{\circ}, 16.38^{\circ}, 18.46^{\circ}, 21.05^{\circ}, 23.53^{\circ}$ and $29.14^{\circ}$ which indicate crystalline nature of pure drug. But when LNZ was incorporated into the polymers, after the preparation of agglomerates the intensities of the peaks decreases due to the decreased crystallinity of the LNZ in agglomerate form (fig. 5). This was because of dilution with polymers and dilution carried out by the PVPK30 though the intensity of peaks in XRPD was reduced, there is no considerable change in $d$-spacing values suggesting no change in crystal form of drug but crystal habit of the drug might be changed thus suggesting the absence of a polymorphic transition. How theta ever, no obvious peaks representing crystals of LNZ were seen for the solid spherical crystals, indicating the absence of a crystalline structure of LNZ in the formulation.

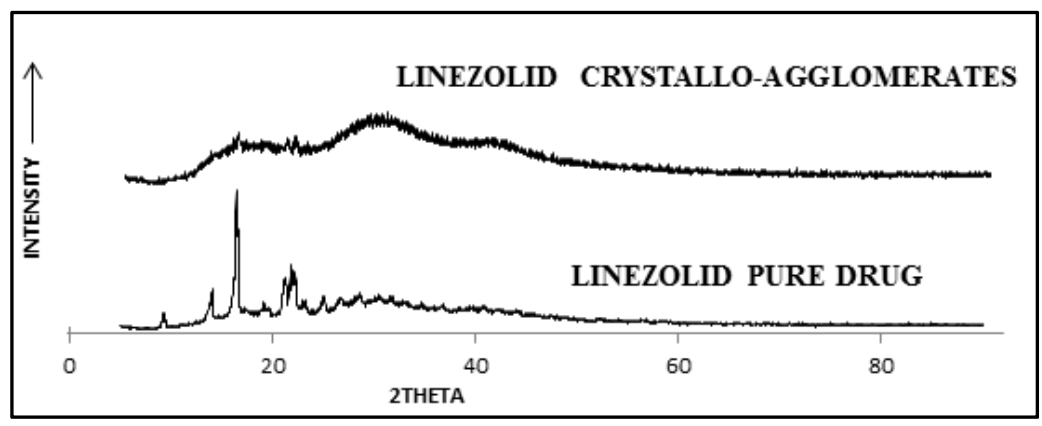

Fig. 5: X-ray powder diffraction pattern of pure linezolid and optimized batch

The DSC thermogram of pure LNZ showed sharp melting endotherm at $180^{\circ} \mathrm{C}$ with the heat of fusion $-120 \mathrm{~J} / \mathrm{g}$. This clearly indicates crystalline nature of the pure drug. In the thermogram of the agglomerates showed a broad endothermic peak at the $178{ }^{\circ} \mathrm{C}$ which corresponds to a loss of water and shifting peak indicating hygroscopic nature of agglomerates. These findings indicated that raw crystals of LNZ have changed for agglomerates during recrystallization Thus DSC results were well supported with XRPD indicating the polymorphic transition of LNZ during recrystallization (fig. 5.6). This clearly indicated crystalline nature of the agglomerates. This observation also confirmed the absence of any chemical interaction of the drug with additives during agglomeration process, further supporting the results of IR spectroscopy. (fig. 1, fig. 2).

Compression studies on agglomerates of LA1, LA2 and LA3 showed deformation of agglomerates instead of a fracture because the agglomerates had lower voids (porosity) showing interarticular slippage during compression. HPMC contributed to deformation of the agglomerates. Along with HPMC adsorbed at the surface of talc, high talc content also imparted deformability to agglomerates. The LA1 agglomerates required more deformation force than did the LA2 and LA3 agglomerates, in agreement with the study performed by Pawar et al.[3]. The consolidation ability of agglomerates is indicated by Mean yield pressure (MyP). In the case of for LA2, LA3 MyP was less than LA1, and high pressure required to deformation of LA1 (table 5). An increase in the talc percentage increased the deformation force. Tensile strength $(\sigma t)$ determine the ability of solid which withstand fracture. LA1 has high tensile strength than
LA2, LA3, this indicates the bonding between talc and drug molecule more in LA1 (table 6).

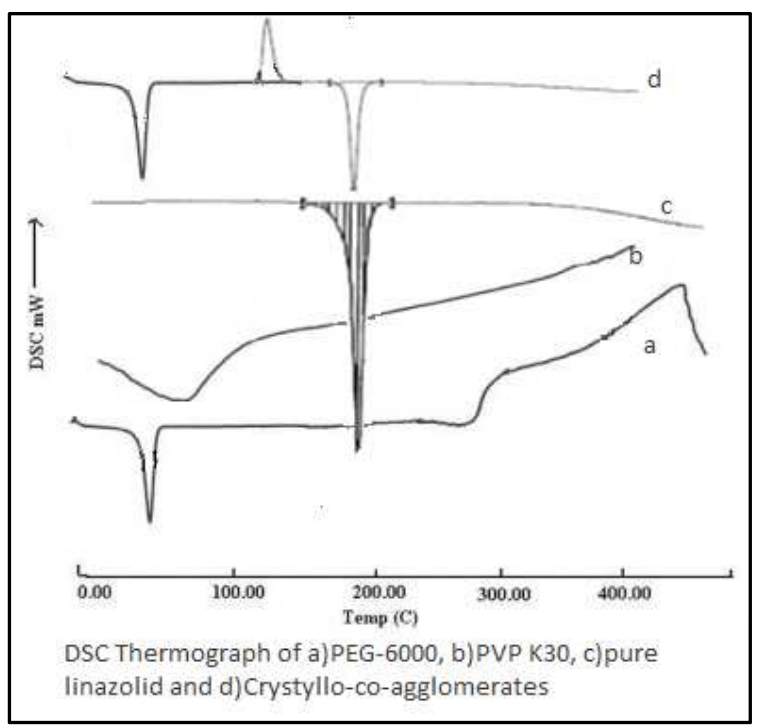

Fig. 6: DSC thermogram of linezolid and optimized batch

Table 5: Compression properties of agglomerates

\begin{tabular}{llll}
\hline S. No. & Batch code & Slope (Ky) & MyP \\
\hline 1 & LA1 & 1.023 & 0.977 \\
2 & LA2 & 1.743 & 0.679 \\
3 & LA3 & 1.685 & 0.593 \\
\hline
\end{tabular}

Table 6: Pressure-tensile strength ( $\sigma \mathrm{t})$ relationship data

\begin{tabular}{lllll}
\hline S. No. & Pressure in Tons & \multicolumn{2}{l}{ Tensile Strength( $\boldsymbol{\sigma t}$ ) } & LA2 \\
\cline { 3 - 5 } & & LA1 & 10.708 & 10.993 \\
\hline 1 & 0.5 & 11.357 & 11.301 & 11.194 \\
2 & 0.7 & 11.804 & 11.673 & 11.819 \\
3 & 1.0 & 12.210 & 12.614 & 12.760 \\
4 & 1.2 & 12.590 & 12.361 \\
5 & 1.5 & 12.712 & 12.485 & 12.452 \\
6 & 3.0 & 13.292 & 12.532 & \\
\hline
\end{tabular}


The release of drug from agglomerates was more than $75.00 \%$, within 60 min. $75.71 \pm 2.69 \%, 86.88 \pm 3.31 \%$ and $90.88 \pm 2.54 \%$ drug was released from agglomerates LA1, LA2 and LA3 respectively. Whereas from compacts prepared of agglomerates more than $67.00 \%$, within $60 \mathrm{~min} .67 .11 \pm 2.69 \%, 86.02 \pm 2.88$ and $90.62 \pm 2.84$ drug was released from compacts LA1, LA2 and LA3 respectively. The time required for drug release over a period of $60 \mathrm{~min}$, is as LA1 $>$ LA2 $>$ LA3. LA3 shows fast drug release than LA1 and LA2, due to solubilization of drug due to more concentration of PVPK30 and less concentration of talc the data were expressed as mean $\pm \mathrm{SD}$ where $n=3$ (fig. 7, 8.). In this case, it was clearly evident that talc was not the sole factor retarding drug release (LA1). Predominantly, the extent of drug-diluents bonding in the compact $(\sigma \mathrm{t})$ determined the release of the drug. This indicates that there was a strong drugdiluent (talc) interaction and amount of HPMC in the compact. Use of talc in the system retarded the release of the drug because of talc's hydrophobic nature.

Very few researchers have prepared miniscular dosage forms by using excipients with a large surface area [27, 28]. Pawar et al. designed a miniscular dosage form for ibuprofen-talc byCCA. Mainly, recrystallization of the drug during agglomeration generates the miniscular dosage form. The miniscular dosage form of Linezolidtalc in this new study showed sustained drug release fitting the Higuchi matrix model, whereas sustained zero-order drug release was reported for ibuprofen-talc [29].

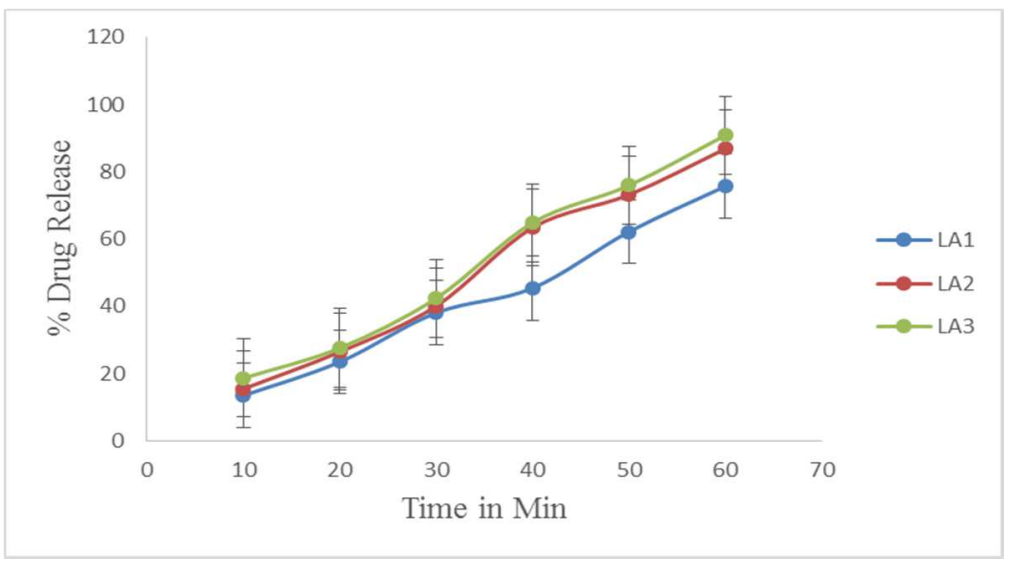

Fig. 7: Drug release study from agglomerates, Results are mean of three determination \pm SD, Where, LA1: linezolid+talc (1:1), LA2 (linezolid+talc (1:0.75), LA3: linezolid+talc $(1: 0.5)$

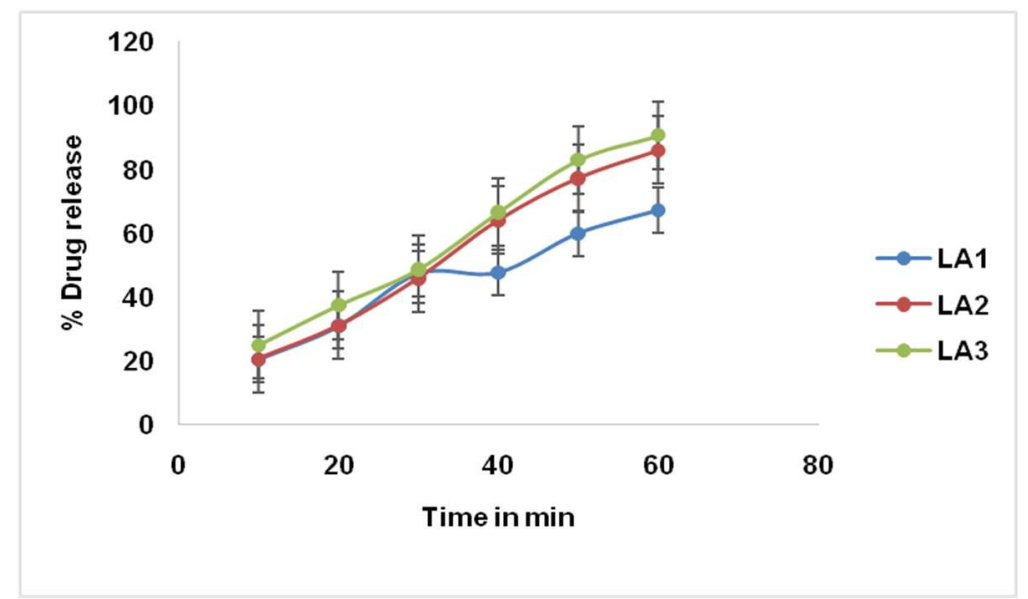

Fig. 8: Drug release study from compressed tablet of agglomerates, Results are mean of three determination \pm SD, Where, LA1: linezolid+talc (1:1), LA2 (linezolid+talc (1:0.75), LA3: linezolid+talc (1:0.5)

\section{CONCLUSION}

The present study revealed that CCA of LNZ prepared with DCM and HPMC/PEG/PVP K30 exhibited improved micrometric properties, compressibility and in addition to improving solubility and dissolution rate. This technique might be applicable for producing oral solid dosage forms of LNZ with improved compressibility, solubility and dissolution rate. Thus instead of preparation of granules, the formation of agglomerates of linezolid would be expected to modify and improve physicochemical, biopharmaceutical and tabletting properties.

\section{ACKNOWLEDGEMENT}

The authors are also thankful to Shivaji University, Kolhapur for providing Minor research grant for this project.

\section{CONFLICT OF INTERESTS}

Declared none

\section{REFERENCES}

1. Shangraw RF. Compressed tablets by direct compression. In: Lieberman HA, Lachman L, Schwartz JB. editors. Pharmaceutical dosage forms: tablets. Vol. I. 2nd ed. New York: Marcel Dekker; 1989. p. 195-246.

2. Ali N, Maryam M, Davood H, Mohammad BJ. Preparation of agglomerated crystals for improving flowability and compactibility of poorly flowable and compatible drugs and excipients. Powder Technol 2007;175:73-81.

3. Paradkar A, York P. Crystal engineering and particle design for the powder compaction process In Celik M. editors. 
Pharmaceutical powder compaction technology. 2nd ed. London: Informa healthcare; 2011. p. 235-52.

4. Hassanpour A, Ghadiri M. Distinct element analysis and experimental evaluation of heckle analysis of bulk powder compression. Powder Technol 2004;141:251-61.

5. Denny PJ. Compaction equations: a comparison of the Heckel and Kawakita equations. Powder Technol 2002;127:162-72.

6. Kawashima Y. Spherical crystallization as a novel particle design technique for oral drug delivery system. Chin Pharm J 1989;41:163-72.

7. Yadav VB, Yadav AV. Comparative tabletting behavior of carbamazepine granules with spherically agglomerated crystals prepared by spherical crystallisation technique. Int J ChemTech Res 2009;1:476-82.

8. Kadam SS, Mahadik KR, Paradkar AR. Inventors a process for making agglomerates for use as or in a drug delivery system. Indian Patent 183036; 1997.

9. Kadam SS, Mahadik KR, Paradkar AR. Inventors a process for making agglomerates for use as or in a drug delivery system. Indian Patent 183481; 1997.

10. Pawar AP, Paradkar AR, Kadam SS, Mahadik KR. Crystallo-coagglomeration: a novel technique to obtain ibuprofenparacetamol agglomerates. AAPS PharmSciTech 2004;5:44.

11. Sarfaraz MD, Arshad K, Doddayya H, Reddy SR, Udupi RH. Particle design of aceclofenac-disintegrant agglomerates for direct compression by crystallo-CoAgglomeration technique. Asian J Pharm Tech 2011;1:40-8.

12. Nokhodchi A, Maghsoodi M. Preparation of spherical crystal agglomerates of naproxen-containing disintegrant for direct tablet making by spherical crystallization technique. AAPS PharmSciTech 2008;9:54-9.

13. Keshwani B, Jaimini M, Sharma D. Spherical crystallization: a revolution in the field of particle engineering. Int J Curr Pharm Res 2015;7:19-25.

14. Chaturvedi A, Sharma $P$, Bansal M. A review on recent advancement in crystallo-co-agglomeration. Adv Biol Res 2011;5:273-81.

15. Yadav AV, Yadav VB. Designing of pharmaceuticals to improve physiochemical properties by spherical crystallization technique. J Pharm Res 2008;1:105-12.

16. Higuchi T, Connors KA. Phase-solubility techniques. Adv Anal Chem Inst 1965;4:117-212.
17. Shendge RS, Sayyad FJ. Formulation development and evaluation of colonic drug delivery system of budesonide microspheres by using spray drying technique. J Pharm Res 2013;6:456-61.

18. Ganeshan V, Ethiraj T. Preparation and characterization of crystals of prulifloxacin. Int J Pharm Pharm Sci 2015;7:307-10.

19. Heckel RW. Density-pressure relationships in powder compaction. Trans Metall Soc AIME 1961;221:671-5.

20. Heckel RW. An analysis of powder compaction phenomena. Trans Metall Soc AIME 1961;221:1001-8.

21. Rubinstein MH, Musikabhumma P. A universal friability test for tablet granules. Pharm Acta Helv 1978;53:125-9.

22. Yadav AA, Yadav DS, Karekar PS, Pore YV, Gajare PS. Enhanced solubility and dissolution rate of Olmesartan medoxomil using the crystallo-co-agglomeration technique. Pharm Sinica 2012;3:160-9.

23. Patil S, Pawar A, Shahoo SK. Effect of additives on the physicochemical and drug release properties of pioglitazone hydrochloride spherical agglomerates. Trop J Pharm Res 2012;11:18-27.

24. Kawashima Y. Crystal modification of phenytoin with polyethylene glycol for improving mechanical strength, dissolution rate and bioavailability by spherical crystallization technique. Chem Pharm Bull 1986;34:3376-83.

25. Jadhav NR, Pawar AP, Paradkar AR. Design and evaluation of deformable talc agglomerates prepared by crystallo-coagglomeration technique for generating the heterogeneous matrix. AAPS PharmSciTech 2007;8:1-7.

26. Lalla JK, Bhat SU. A look at process costing and cost-effectiveness of a pharmaceutical formulation. Indian Drugs 1995;32:551-60.

27. Sanghavi NM, Sivanand R, Kotwaney HN. Dissolution pattern of miniscular sulfisoxazole. Indian J Pharm Sci 1979;41:116-7.

28. Alsaidan SM, Abdulhakeem AA, Eshra AG. The improved dissolution rate of indomethacin by adsorbents. Drug Dev Ind Pharm 1998;24:389-94.

29. Pawar AP, Paradkar AR, Kadam SS, Mahadik KR. Agglomeration of ibuprofen with talc by novel crystallo-co-agglomeration technique. AAPS PharmSciTech 2004;5:30-5.

\section{How to cite this article}

- Atul M Kadam, Shitalkumar S Patil. Improvement of micromeritic, compressibility and solubility characteristics of linezolid by crystallo-co-agglomeration technique. Int J Appl Pharm 2017;9(4):47-53. 